Research Article

\title{
Citrus Lemon Juice Mediated Preparation of AgNPs/Chitosan- Based Bionanocomposites and Its Antimicrobial and Antioxidant Activity
}

\author{
S. Rajeshkumar (iD \\ Nanobiomedicine Lab, Department of Pharmacology, Saveetha Dental College and Hospitals, SIMATS, Chennai 600077, India \\ Correspondence should be addressed to S. Rajeshkumar; ssrajeshkumar@hotmail.com
}

Received 2 July 2021; Revised 15 September 2021; Accepted 24 September 2021; Published 6 October 2021

Academic Editor: Ali Khorsand Zak

Copyright (c) 2021 S. Rajeshkumar. This is an open access article distributed under the Creative Commons Attribution License, which permits unrestricted use, distribution, and reproduction in any medium, provided the original work is properly cited.

\begin{abstract}
Nanoparticles are important advanced materials with numerous uses in a variety of fields. Novel antibacterial nanocomposites with synergistic capabilities can be created by combining metal nanoparticles with biopolymers of various functionalities. This research evaluates an antimicrobial and antioxidant-rich chitosan-based silver nanocomposite synthesized by using citrus lemon extract as a reducing and capping agent. UV-vis spectrophotometer, scanning electron microscope, elemental dispersive analysis, X-ray diffraction assay, atomic force microscope, Fourier transform infrared spectroscopy, UV-near infrared spectroscopy, and transmission electron microscopy were used to characterize the chitosan-based silver nanocomposite (CS-Ag nanocomposite). The nanocomposite synthesized is used to demonstrate antioxidant and antimicrobial activity against fungal pathogens.
\end{abstract}

\section{Introduction}

Nanoparticles and nanocomposites are employed in a variety of applications across a wide range of industries. Silver nanoparticles have a wide range of applications as antimicrobial agents, including wastewater treatment, food preservation, clothe and textile preservation, detergents, and medical implants [1]. Plant extracts can be used to make silver nanoparticles that are both environmentally friendly and costeffective [2]. Plant extracts such as Boerhavia diffusa leaves [3], Piper nigrum stem and leaf [4], Avicennia marina mangrove plant [5], Cissus quadrangularis [6], Parthenium hysterophorus [7], Manilkara zapota seeds [6], and Chrysanthemum flower extracts [8] and fruit extracts of pomegranate [9], Dillenia indica [10], Solanum xanthocarpum [11], and Crataegus douglasii [12] were employed, and it was used for antibacterial, antifungal, and antioxidant properties. Chitosan is a harmless, biodegradable polymer found in natural resources such as crab and prawn shells, as well as other marine and terrestrial invertebrates. Because of its excellent antibacterial and biocompatibility qualities, it has a wide range of biological uses [13]. Once silver nanoparticles are mixed with other polymers, they can generate nanocomposites with a variety of benefits. The antimicrobial activity of silver with agar against Listeria monocytogenes and Escherichia coli [14], the antimicrobial activity of polysulfone with silver to inhibit biofilm growth on downstream membrane surfaces [15], and the bacterial cellulose with silver magnetic nanocomposites are used for high antimicrobial activity against the model microbes Escherichia coli and Bacillus subtilis [16], and agar-based silver nanocomposite films are prepared using red alga Gracilaria dura to control Bacillus pumilis bacterial growth [17]. Chitosan-based silver nanocomposites, which include chitosan with silver nanoparticles, are being developed for a variety of commercial uses. The Bacillus subtilis-based silver nanocomposites were tested against disease-causing pathogens such as Staphylococcus aureus, Pseudomonas aeruginosa, Aspergillus niger, and Candida albicans [18], and the chitosan-based silver and fluoride nanocomposites were tested against disease-causing pathogens such as Staphylococcus aureus, Escherichia coli, and Candida albicans using microdilution technique [19]. In this research, we employed citrus lemon juice to synthesize chitosan-based silver nanocomposites (CS-Ag nanocomposite). UV-vis spectrophotometer, scanning electron 


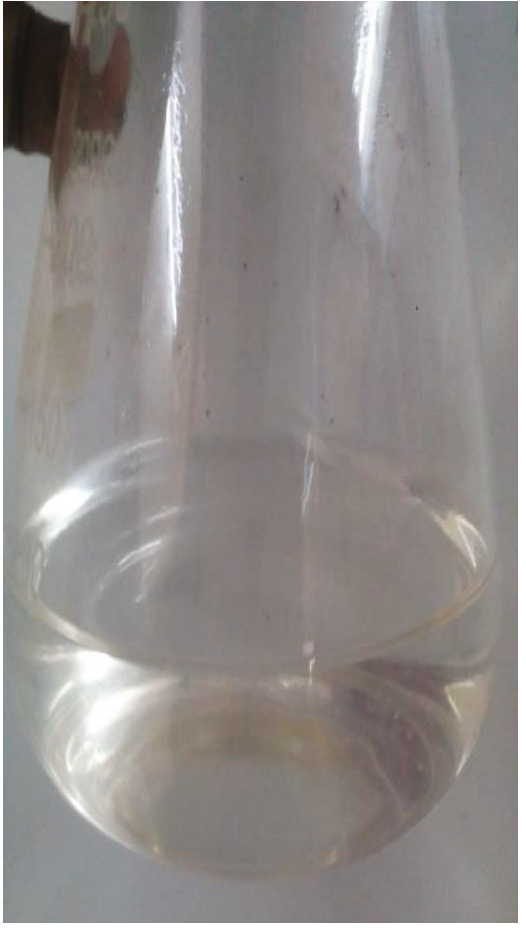

(a)

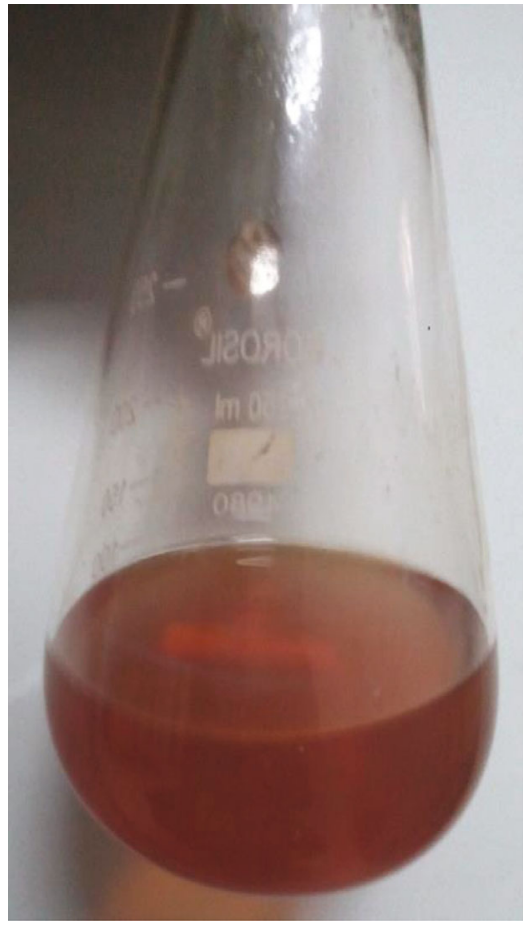

(b)

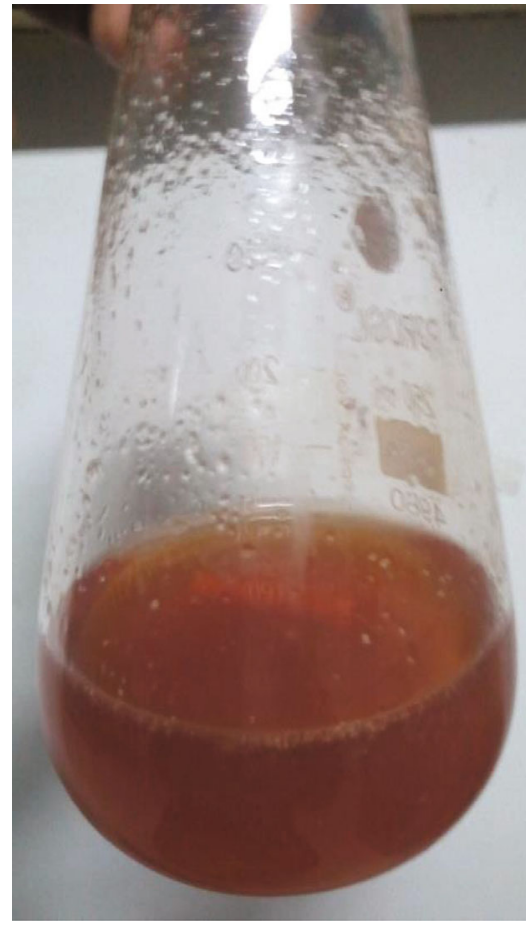

(c)

Figure 1: Visual observation: (a) initial observation of lemon extract and $\mathrm{AgNO}_{3}$; (b) color change after 2 hours; (c) color change after adding chitosan.

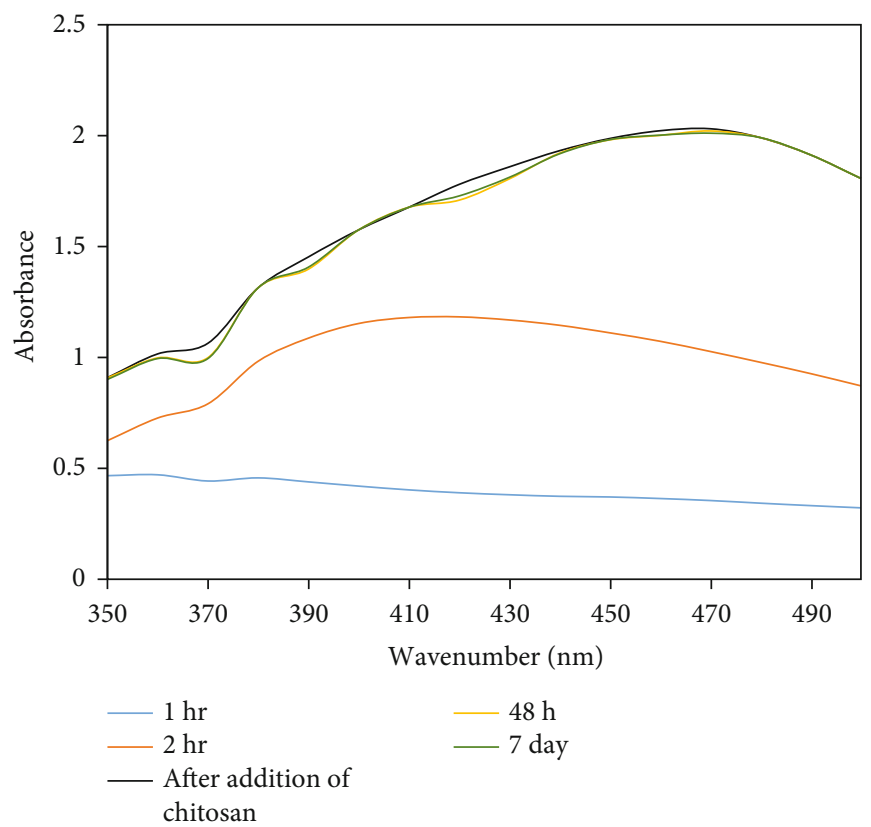

FIGURE 2: UV-spectrum of CS-Ag nanocomposites.

microscope, elemental dispersive analysis, X-ray diffraction assay, atomic force microscope, Fourier transform infrared spectroscopy, and UV-near infrared spectroscopy were used to characterize the nanocomposites. Finally, antioxidant and antibacterial activity against fungal infections is performed to the nanocomposites which have been synthesized.

\section{Materials and Methods}

2.1. Preparation of Fruit Extract. Lemon fruit was purchased from Vellore market and washed thoroughly under tap water. The lemons were cut into four pieces, and the fresh juice was extracted, filtered using Whatman No.1 filter paper. 


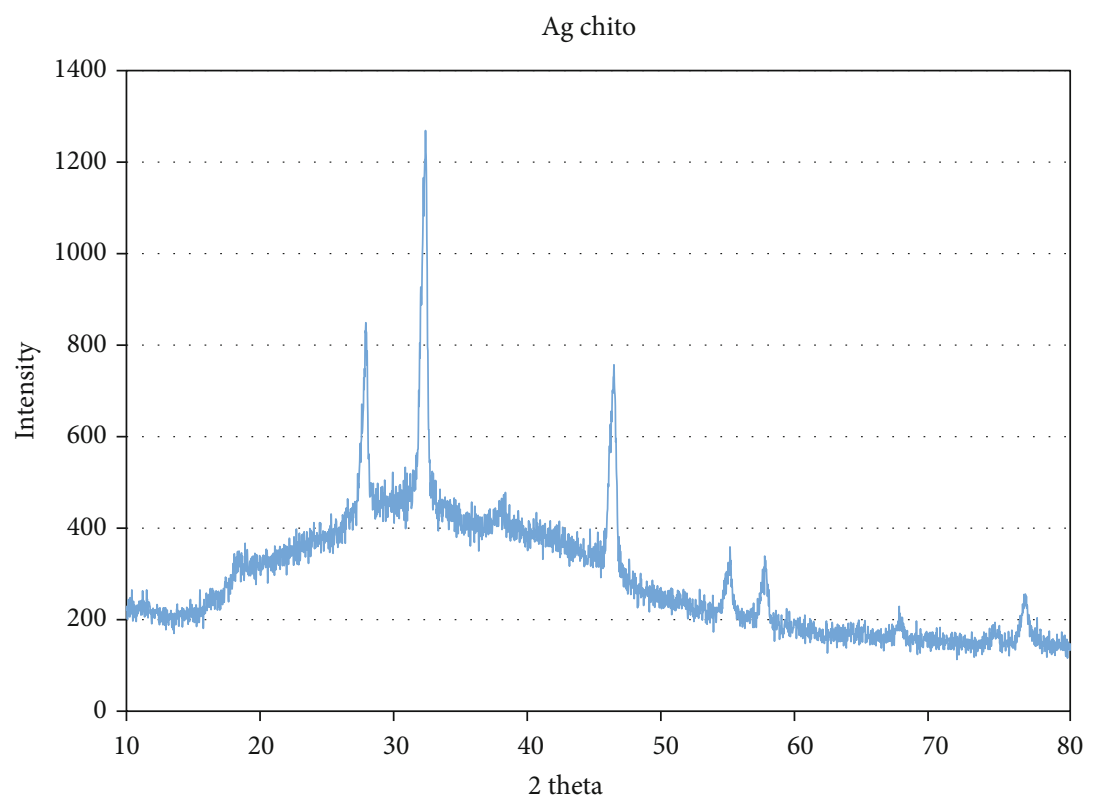

FIGURE 3: XRD spectrum of CS-Ag nanocomposite which showed broadened peak due to the presence of chitosan polymer.
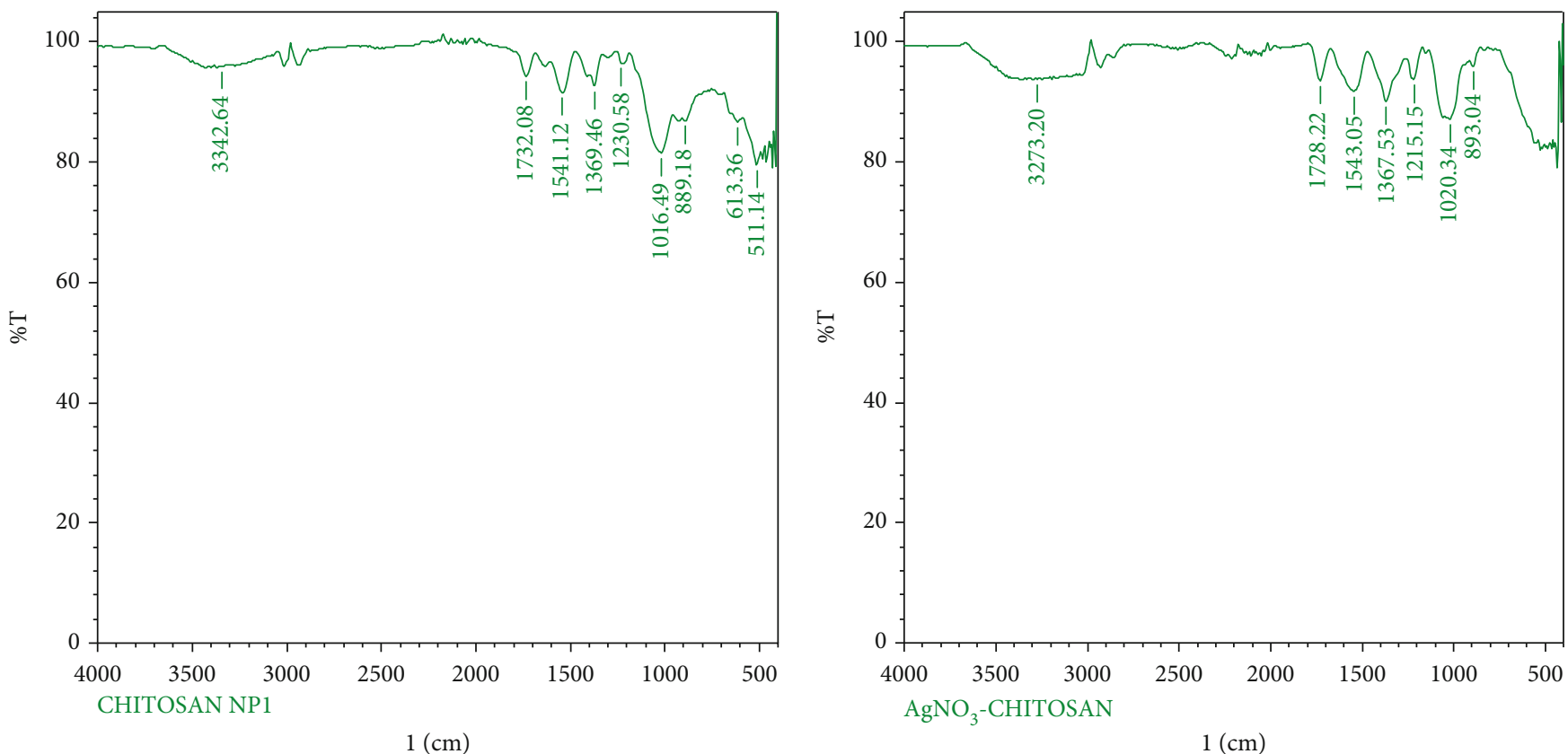

FIGURE 4: FTIR spectra of chitosan and chitosan-based silver nanocomposites.

2.2. Synthesis of CS-Ag Nanocomposite. To synthesize CS-Ag nanocomposite, $1 \mathrm{mM}$ of silver nitrate was added to $95 \mathrm{ml}$ of distilled water. $5 \mathrm{ml}$ of filtered fresh lemon juice extract was added to $95 \mathrm{ml}$ of silver nitrate solution. The reaction mixture was placed on a magnetic stirrer at $700 \mathrm{rpm}$ for $3 \mathrm{~h}$ to detect color changes. Figure 1 depicts a visual observation of the synthesized silver nanoparticle solution. After $3 \mathrm{~h}$, $0.25 \mathrm{~g}$ of chitosan was added to the solution and stirred for $3 \mathrm{~h}$ in a magnetic stirrer at $700 \mathrm{rpm}$. The CS-Ag nanocomposite solution was then centrifuged for 10 minutes at $8000 \mathrm{rpm}$. The pellet was collected after centrifugation, and the supernatant was discarded.
2.3. Characterization of CS-Ag Nanocomposite. During the reduction of $\mathrm{Ag}+$ to $\mathrm{Ag} \mathrm{NPs}, \mathrm{UV}$-vis absorption analysis was carried. It was often scanned in the 300-500 nm wavelength range. XRD measurements at $40 \mathrm{kV}$ and $30 \mathrm{~mA}$, equipped with a $\mathrm{Cu}$ anode and a ceramic X-ray tube, were used to assess the crystalline nature and structure of AgNPs incorporated with chitosan. The functional groups present in the CS-Ag nanocomposite were analyzed using FT-IR in the range of $4000-500 \mathrm{~cm}^{-1}$. The microstructure of lemon extract mediated CS-Ag nanocomposite was analyzed using a scanning electron microscope (SEM) and atomic force microscope (AFM) to determine the size shape and 


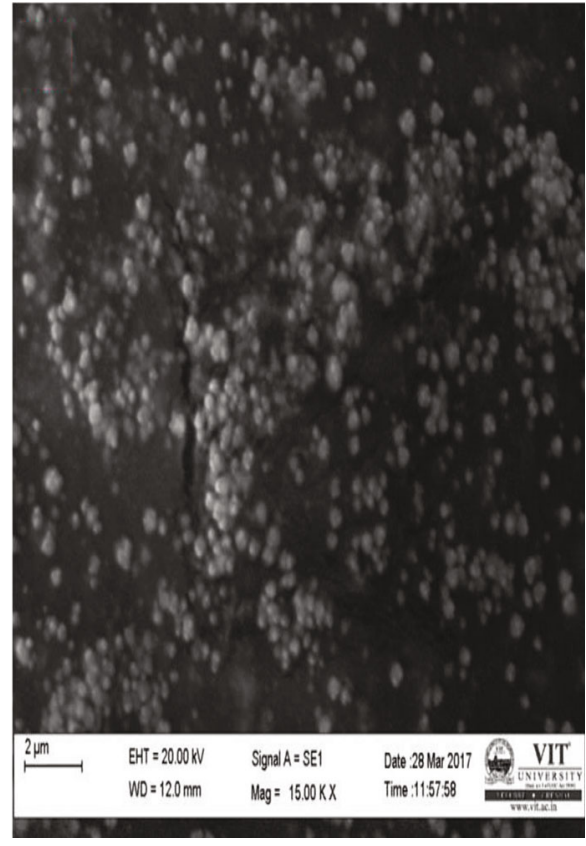

(a)

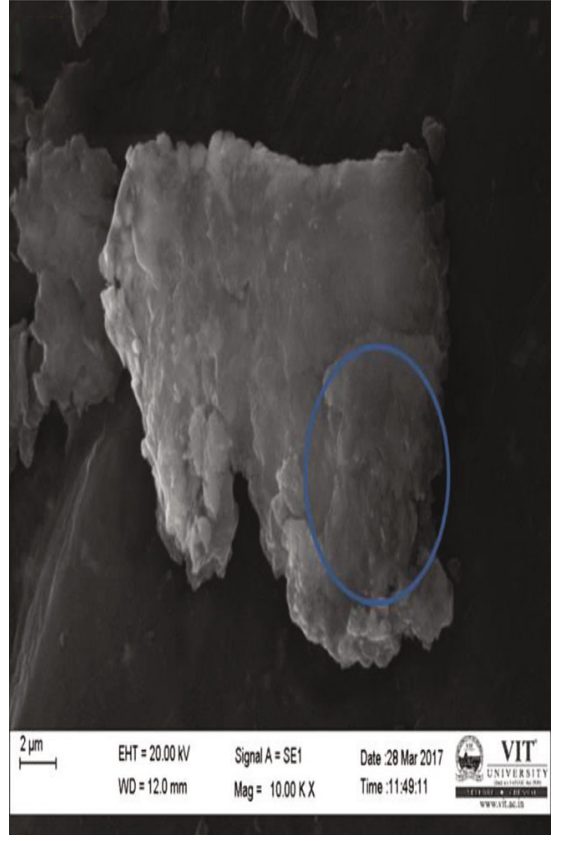

(b)

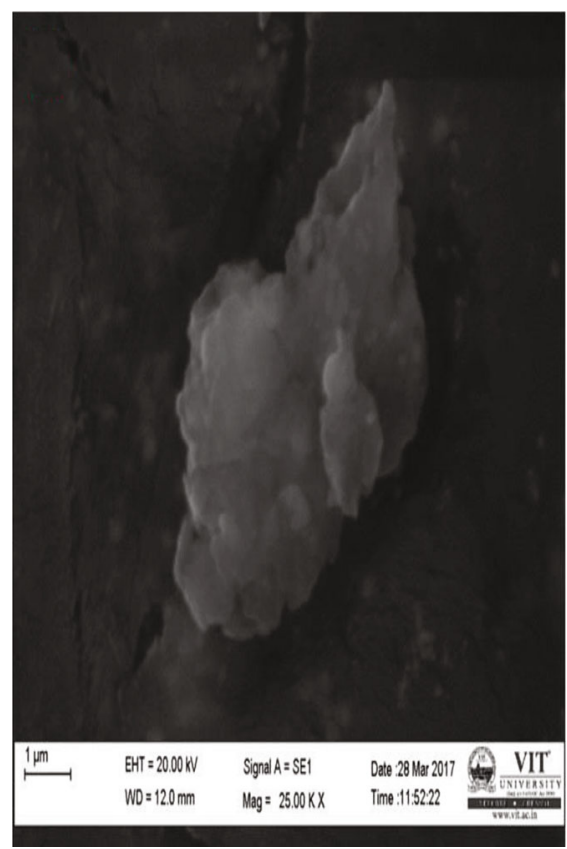

(c)

FIGURE 5: SEM images of CS-Ag nanocomposites: (a) chitosan-silver nanoparticles with the size range of $200 \mathrm{~nm}$; (b) SEM image of silver nanoparticles embedded in chitosan polymer; (c) SEM image of chitosan polymer.

morphology of the CS-Ag nanocomposite. Energydispersive X-ray analysis spectrum was also recorded.

2.4. Antibacterial Activity. The agar well diffusion method was used to test antibacterial activity. The Mueller-Hinton agar was sterilized and prepared. The Muller-Hinton agar was poured and solidified in aseptic condition on clean and sterilized Petri plates. Swabs of pathogenic organisms such as Streptococcus sp, Rhizobium radiobacter, Klebsiella pneumoniae, and Escherichia coli were cultured in liquid broth. After 5 minutes, wells were punched in the agar plate with a $5 \mathrm{~mm}$ gel puncher. The results were seen after different concentrations of nanoparticles of $25 \mu \mathrm{l}, 50 \mu \mathrm{l}$, and $75 \mu \mathrm{l}$ were loaded into each well and incubated for 24 hours. The antibacterial activity was determined by measuring the diameter of the inhibitory zone generated around the well and recording the mean results.

2.5. Antifungal Activity. The agar well diffusion method was used to test antifungal activity. Rose Bengal Agar was 

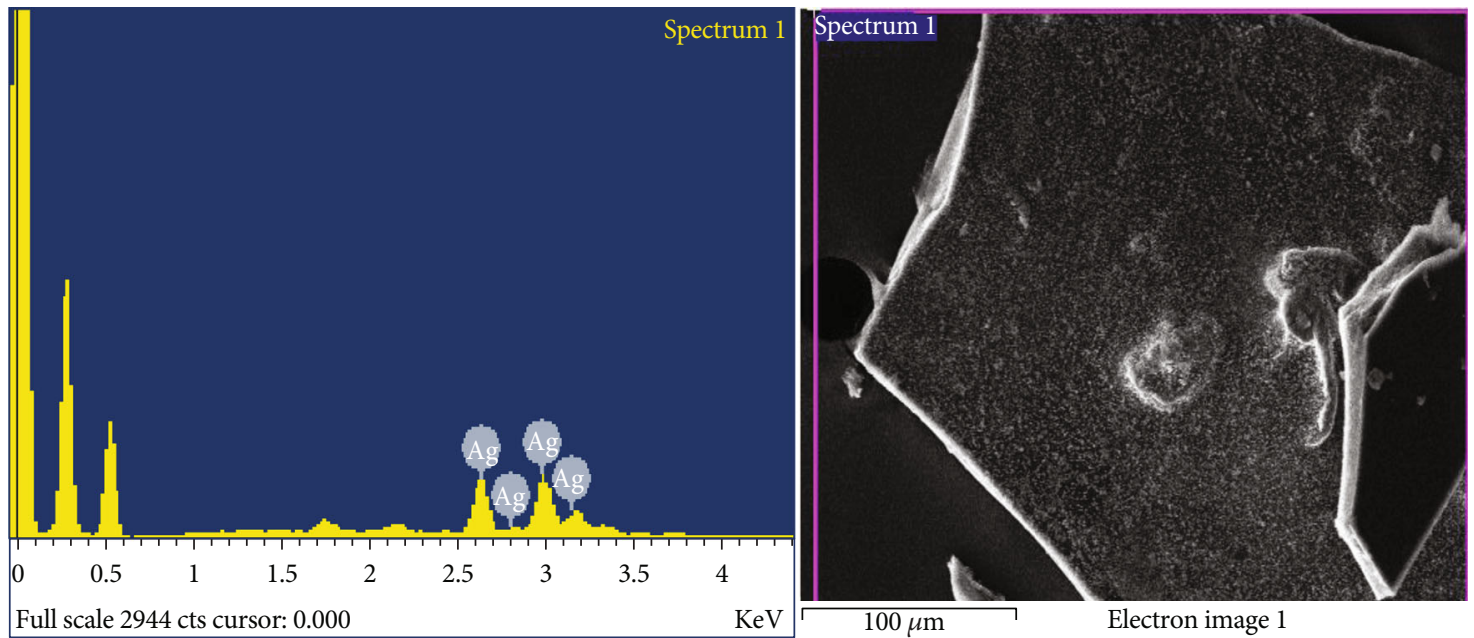

FIGURE 6: EDX spectra of chitosan-silver nanocomposites.

sterilized and prepared. The Rose Bengal Agar was poured and solidified in sterile conditions on clean and sterilized plates. Cultures of pathogenic organisms like Aspergillus niger, Fusarium oxysporum, and Aspergillus fumigatus were inoculated and swabbed. After 5 minutes, wells were punched in the agar plate with a $5 \mathrm{~mm}$ gel puncher. Different concentrations of nanoparticles of $25 \mu \mathrm{l}, 50 \mu \mathrm{l}$, and $75 \mu \mathrm{l}$ were loaded into each well and incubated for 24 hours before the data were analyzed. The antifungal activity was determined by measuring the diameter of the inhibitory zone that formed around the well and recording the mean results.

2.6. Antioxidant Activity of Nanocomposites. Based on previous findings [8], the free radical scavenging activity of the lemon juice mediated CS-Ag nanocomposite was evaluated using the 1,1-diphenyl-2-picrylhydrazyl (DPPH) assay. $0.78 \mathrm{mg}$ of DPPH was added to $10 \mathrm{ml}$ of methanol to make DPPH. Five different concentrations of extracts $(20 \mu \mathrm{l}$, $40 \mu \mathrm{l}, 60 \mu \mathrm{l}, 80 \mu \mathrm{l}$, and $100 \mu \mathrm{l}$ ) were added to $2 \mathrm{ml}$ of this DPPH solution. The antioxidant ascorbic acid was utilised as a standard. The samples were incubated for $30 \mathrm{~min}$ in dark. The absorbance was measured using a spectrophotometer at $517 \mathrm{~nm}$. The blank was prepared without the addition of extract. Lower absorbance of the reaction mixture indicates higher free radical scavenging activity. The capability to scavenge the DPPH radical was calculated using the following equation:

$$
\text { DPPH Scavenged }(\%)=\frac{A \text { control }-A \text { test } \times 100}{A \text { control }},
$$

where $A$ control is the absorbance of the control reaction and $A$ test is the absorbance in the presence of the sample of the extracts.

\section{Result and Discussion}

3.1. Color Change and Visual Observation. Figure 1(a) shows the silver nitrate solution, which changed color from pale yellow to brown after adding lemon juice, indicating the syn- thesis of silver nanoparticles. Fruit extracts are a great source for making silver nanoparticles because they quickly change the color of silver nitrate solution into silver nanoparticles [9]. AgNPs were expected to form in the CS-Ag nanocomposite as a result of $\mathrm{AgNO}_{3}$ reduction. Depending on the concentration of AgNPs, the chitosan films loaded with AgNPs turned from pale brown to dark brown. Figure 1(c) depicts the color change of silver nanoparticles in chitosan solution to turbid solution.

3.2. UV-Visible Spectroscopy. The UV-vis absorption spectra of Ag nanoparticles and AgNP-based chitosan nanocomposites are shown in Figure 2. Figure 2 displays a peak at $420 \mathrm{~nm}$, due to the plasma vibrations of silver nanoparticles and another peak at $470 \mathrm{~nm}$ showing some possible interaction between chitosan and silver nanoparticles. The absorption peaks of the UV-vis spectra shifted to a longer wavelength when the particle diameters were increased [20]. Based on the size of the AgNPs, the SPR band at 420$460 \mathrm{~nm}$ represents silver nanoparticles, and the peak increases when chitosan is added to the solution [21, 22]. The nanocomposite was again analyzed for its surface plasmon resonance at $48 \mathrm{~h}$ and $7^{\text {th }}$ day. The peaks are near to the value of after the addition of chitosan values confirms the stability of nanocomposites.

3.3. X-Ray Diffraction Analysis. Figure 3 shows the XRD patterns of the CS-Ag nanocomposite spheres. The (111), (121), and (200), crystallographic planes of the face-centered cubic silver crystals might be attributed to three distinctive peaks of silver nanoparticles corresponding to $2 \theta=\left(28.01^{\circ}\right)$, $\left(32.18^{\circ}\right)$, and $\left(46.16^{\circ}\right)$. The position and relative intensity of all the diffraction peaks of the samples were compatible with the crystalline pattern of silver, indicating that the produced nanoparticles were silver nanoparticles. Furthermore, the chitosan utilised in the synthesis procedure did not induce silver oxides to develop. Since the chitosan polymer and silver nanoparticles were present, the shape of each peak was broadened. 


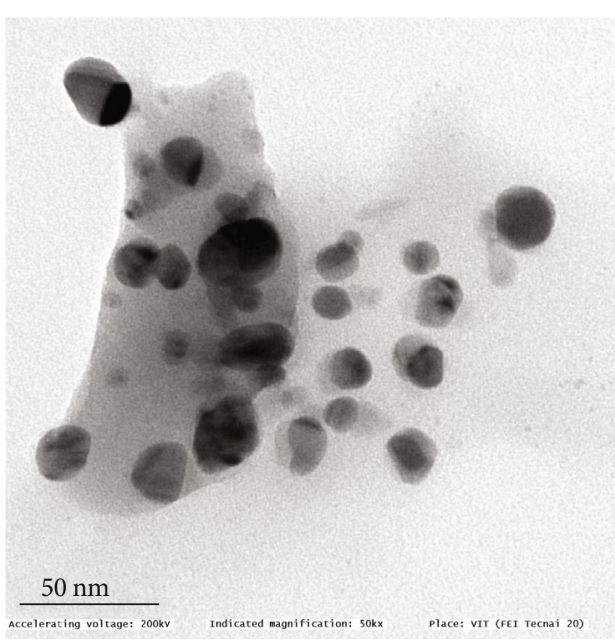

(a)

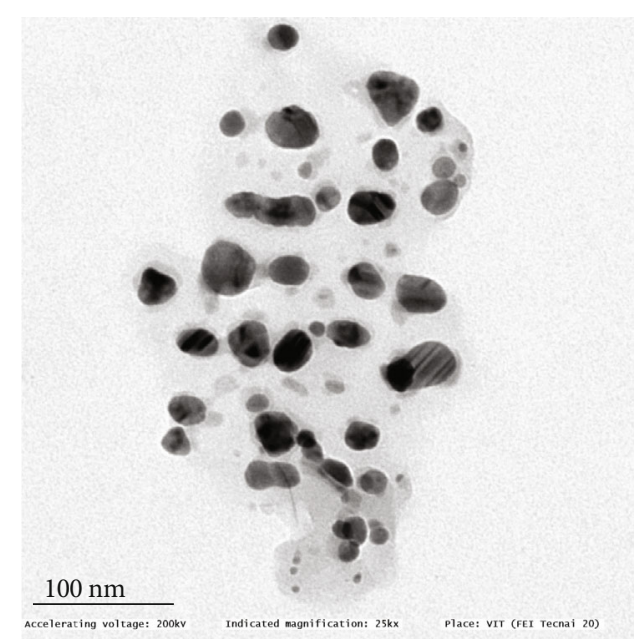

(b)

FIGURE 7: Silver nanoparticles embedded with chitosan nanocomposite: (a) $50 \mathrm{~nm}$ and (b) $100 \mathrm{~nm}$.
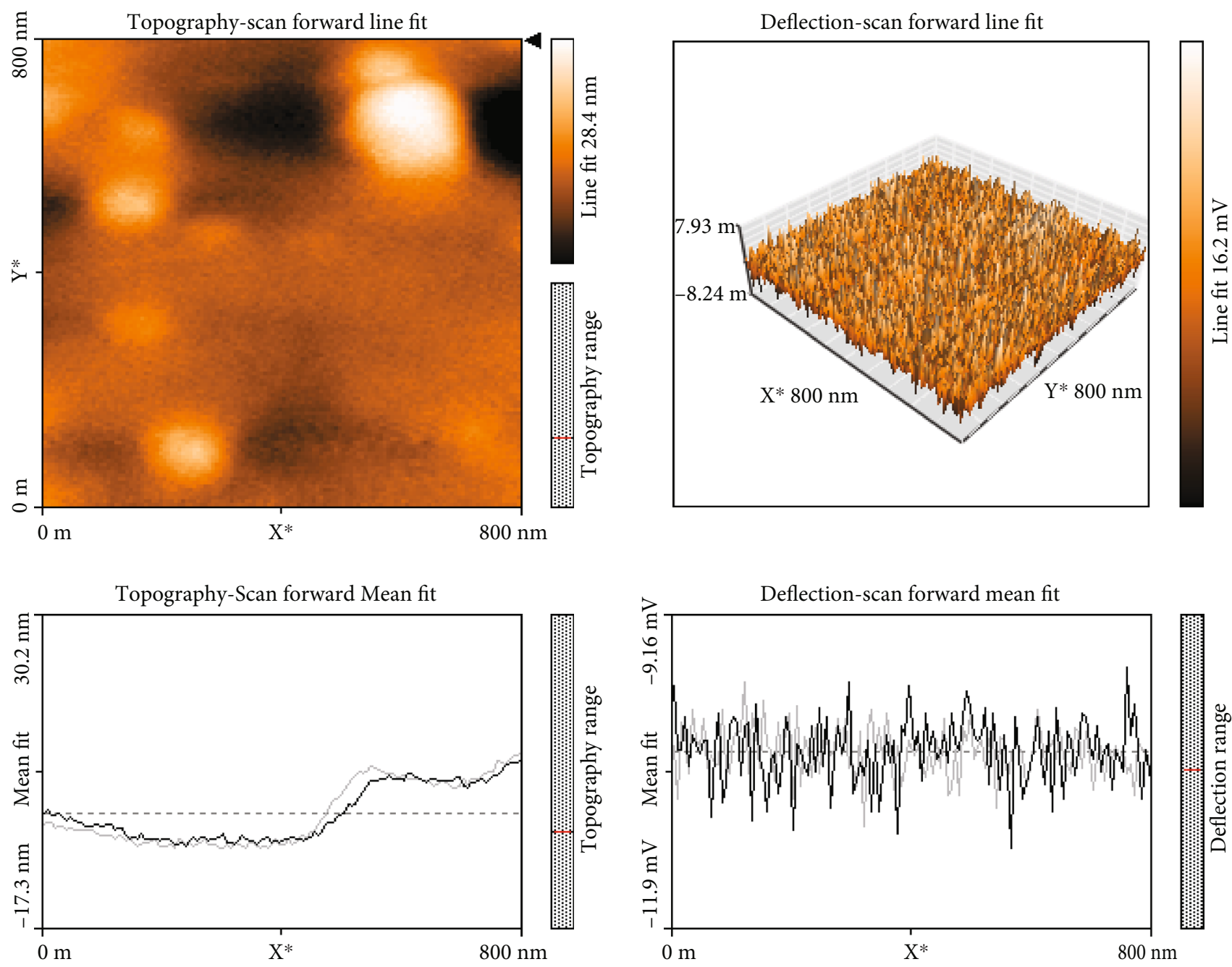

Figure 8: Topographical image by AFM.

3.4. FTIR Spectroscopy. FTIR spectra of CS-Ag nanocomposites are shown in Figure 4. The band between $3273.20 \mathrm{~cm}^{-1}$ was related to the stretching vibration of $=\mathrm{C}-\mathrm{H}$ from the alkyne group. The band between $1728.22 \mathrm{~cm}^{-1}$ was related to stretching vibration of $\mathrm{C}=\mathrm{O}$ from ester groups. The band between $1543.05 \mathrm{~cm}^{-1}$ was related to the bending vibration of 


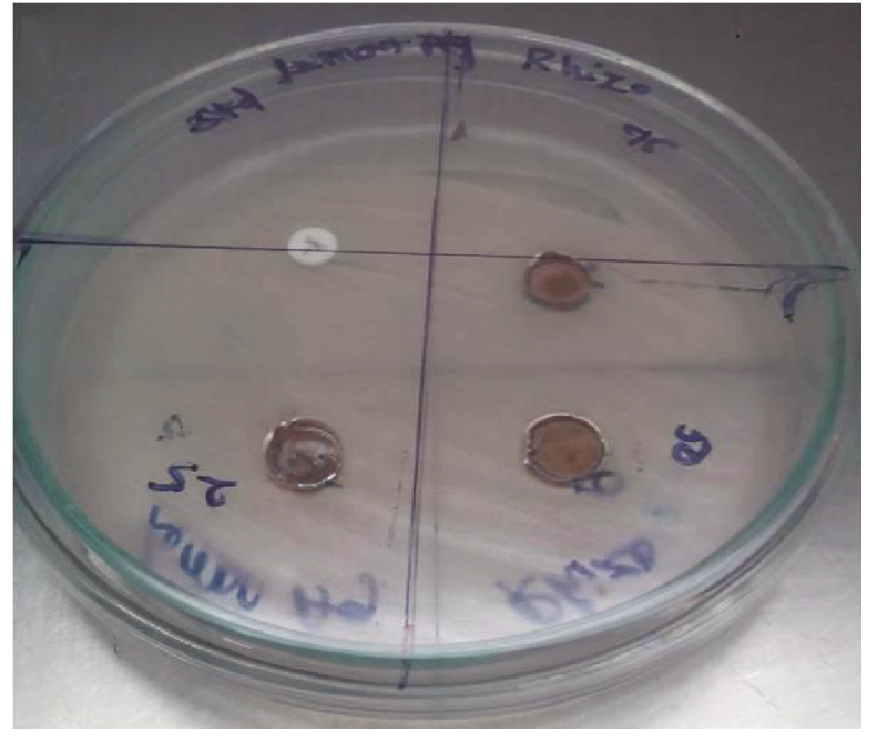

(a)

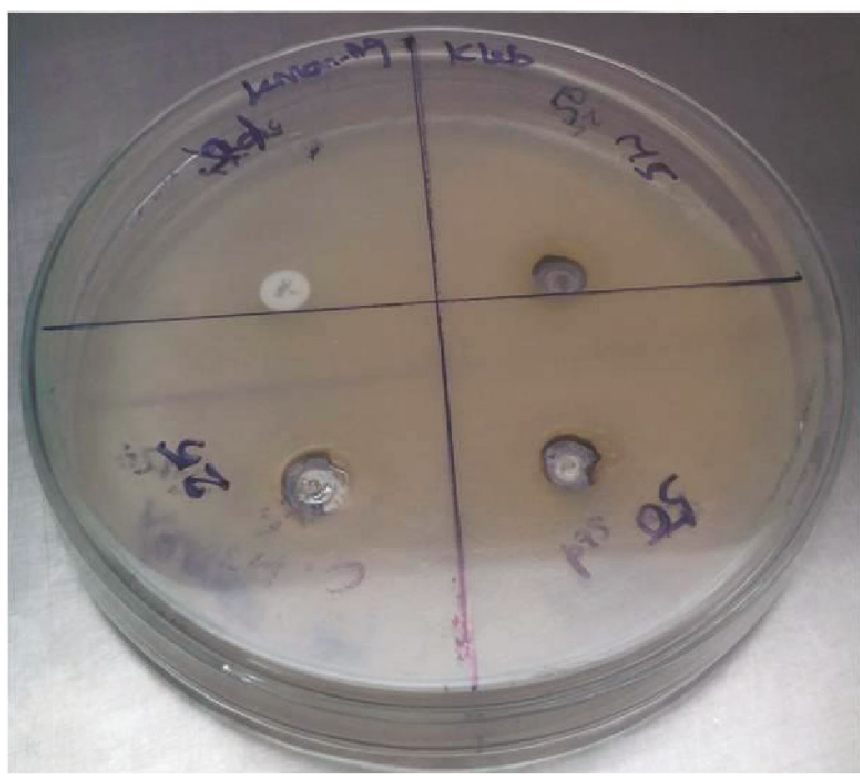

(c)

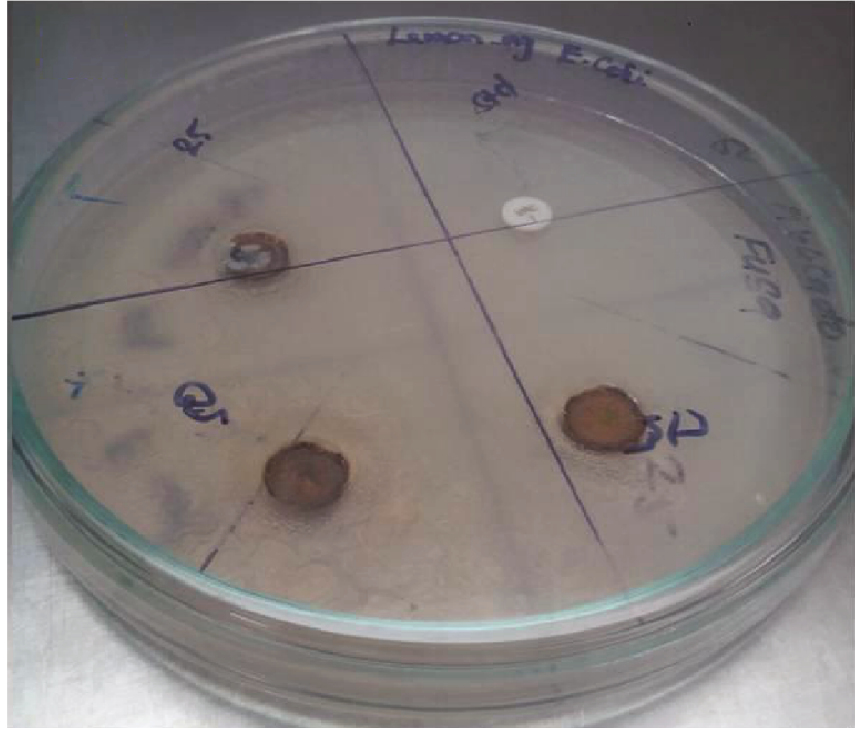

(b)

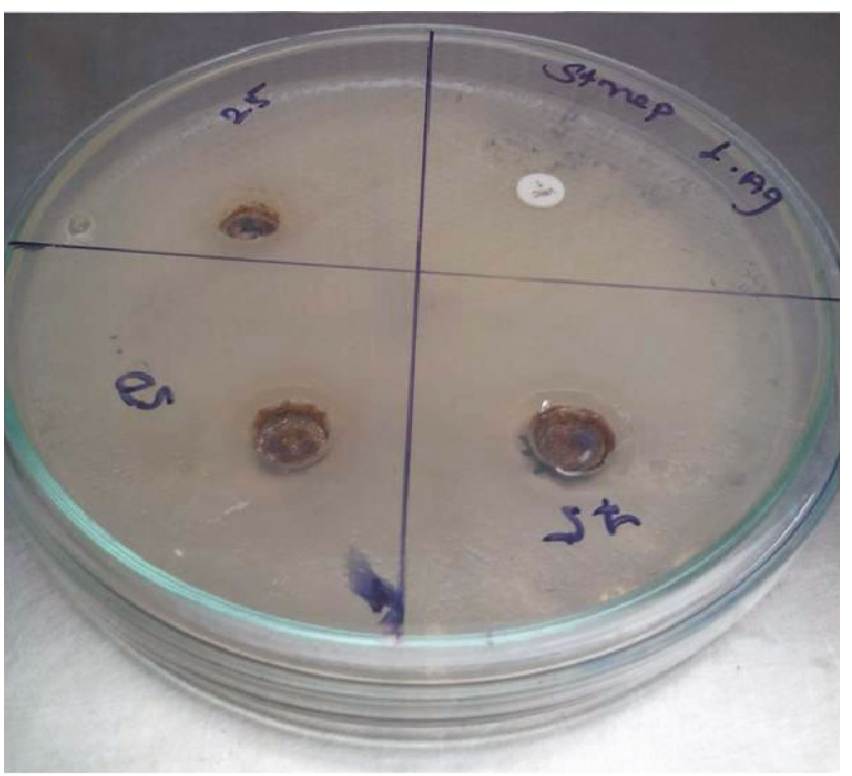

(d)

FIGURE 9: Antimicrobial activity of CS-Ag nanocomposite against (a) Rhizobium radiobacter, (b) Escherichia coli, (c) Klebsiella pneumoniae, and (d) Streptococcus sp.

$\mathrm{N}-\mathrm{H}$ from the amine secondary group. The band between $1367.53 \mathrm{~cm}^{-1}$ was related to bending vibration of $\mathrm{N}=\mathrm{O}$ from the nitro group. The band between $1215.15 \mathrm{~cm}^{-1}$ and $1020.34 \mathrm{~cm}^{-1}$ was related to the stretching vibration of C-O from the ester group. The silver nanoparticles were bonded by protein, which served as a stabilizing agent, either through the free amine group or cysteine residues. These proteins could reduce $\mathrm{AgNO}_{3}$ ions to form silver nanoparticles $[4,23]$.

3.5. Scanning Electron Microscopy. SEM analysis was used to determine the size and shape of nanocomposites. Figure 5(a) clearly shows the SEM micrograph of the silver nanocomposite. The composite particle has an average diameter of about $200 \mathrm{~nm}$ and a uniform particle size. The morphology of the chitosan spheres is shown in Figure 5(b), which have relatively smooth structures when compared to the CS-Ag nanocomposite spheres. The background of chitosan and silver nanoparticle binding is clearly shown in Figures 5(b) and 5(c). Youssef et al. previously reported to synthesize chitosan-based silver and gold nanocomposites [18] in which SEM images clearly show the binding of chitosan and silver nanoparticles.

3.6. EDX Spectrum Analysis. The EDX analysis was used to determine the elements in chitosan-based silver nanocomposites, and the results are shown in Figure 6. The EDX analysis confirmed that the nanocomposites contained approximately $15 \%$ silver and chitosan, $35 \%$ carbon, $44 \%$ oxygen, and $4 \%$ nitrogen. The metallic element, Ag, was 


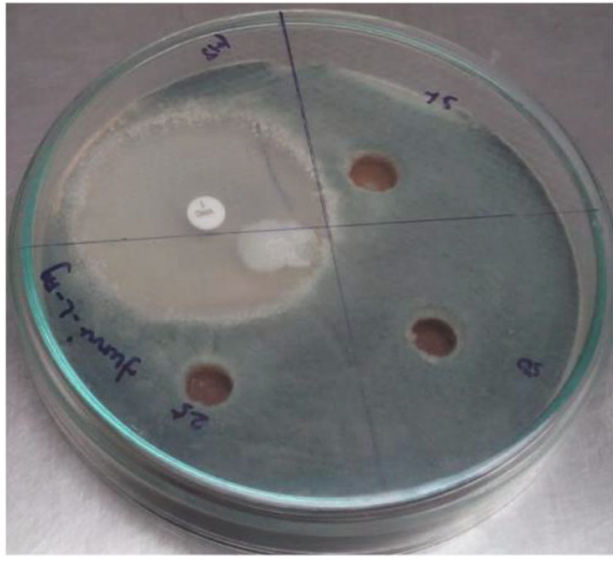

(a)

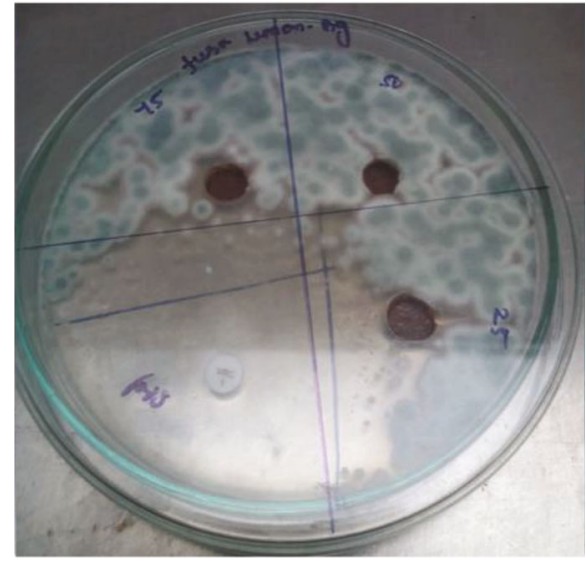

(b)

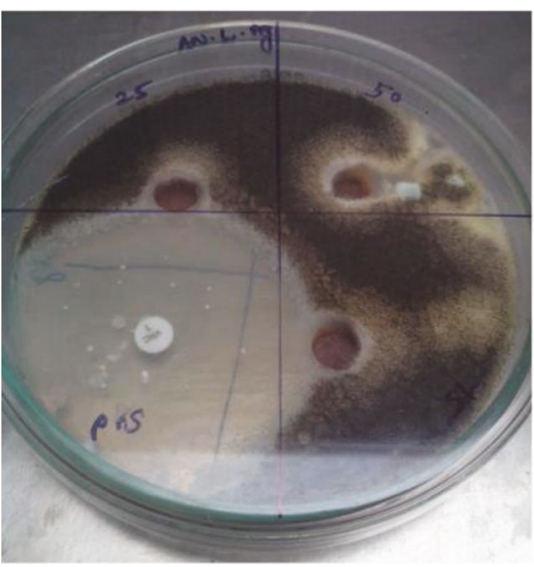

(c)

FIgURE 10: Antifungal activity of chitosan/silver nanocomposite against (a) Aspergillus fumigates, (b) Fusarium oxysporum, and (c) Aspergillus niger.

present in all of the chitosan-based silver nanocomposite films, and the amount of elemental silver in the CS-Ag nanocomposite films increased as the content of AgNP increased.

3.7. TEM Analysis. The morphology of nanoparticles and nanocomposites prepared using green synthesis methods is greatly aided by TEM analysis [24, 25]. The various shapes and sizes produced by silver nanoparticles with chitosan are clarified by TEM analysis. Silver nanoparticles with sizes ranging from 15 to $25 \mathrm{~nm}$ have been discovered, and the size of the nanocomposite is 150 to $200 \mathrm{~nm}$. The chitosan nanocomposites were clearly observed to be embedded with silver nanoparticles, confirming the nanocomposite formation. Figures 7(a) and 7(b) show different spherical-shaped nanoparticles and the background light color, which was discovered to be chitosan.

3.8. AFM Analysis. AFM was used to perform topographical imaging on the surface roughness of the film sample. In Figure 8, an AFM image of silver nanoparticles with chitosan-formed nanocomposites clearly matches the SEM and TEM images.
3.9. Antibacterial Activity. Figure 9 depicts the antibacterial activity of CS-Ag nanocomposite against bacterial pathogens. At a concentration of $75 \mu \mathrm{l}$, the maximum zone of inhibition was obtained in the gram-positive bacteria Streptococcus, with a zone diameter of $12.47 \pm 0.26$. At a concentration of $25 \mu \mathrm{l}$, the gram-negative bacteria Klebsiella pneumoniae had the smallest zone of inhibition, with a zone diameter of $10.27 \pm$ 0.18 . The difference in inhibition is due to the arrangement of cell walls in gram-positive and gram-negative organisms. Streptococcus pneumoniae, which causes pneumonia, wound infection, and skin infection, can be killed by CS-Ag nanocomposites. Silver nanoparticles are an excellent antibacterial agent, and when combined with chitosan, they may be even more effective against other bacterial pathogens $[21,22,26]$.

3.10. Antifungal Activity. Figure 10 depicts the antifungal activity of chitosan/silver nanocomposites against fungus. It had the highest fungal activity against Aspergillus niger and the smallest inhibition zone against Aspergillus fumigatus and Fusarium oxysporum. The fungus' cell wall is very strong, and it may prevent fungal growth from being killed. Silver nanoparticles have been shown to suppress fungal infections on their own [27]. 


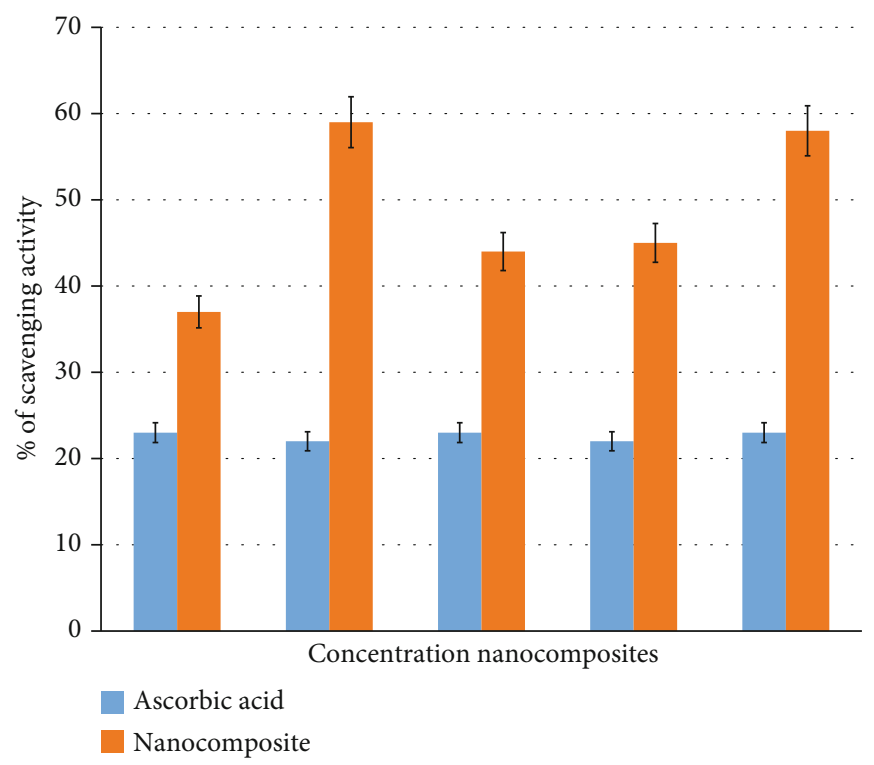

FIGURE 11: Graphical representation of antioxidant activity by DPPH assay.

3.11. Antioxidant Activity by DPPH Assay. The silver nanoparticles synthesized using plant extracts are having very good antioxidant property $[8,28]$. DPPH has been used extensively as a stable free to evaluate reducing substances, and it is a useful reagent for investigating free radical scavenging activity of the component. The free radical scavenging activity by DPPH in graphical representation is shown in Figure 11. It demonstrates the highest antioxidant activity at higher concentration such as $100 \mu \mathrm{l}$ which implies a dosedependent manner (Bedlovicova et al.,2020).

\section{Conclusion}

Lemon juice extract was shown to form a silver nanoparticle-based chitosan nanocomposite. Characterization of the material using XRD, UV-vis spectroscopy, and FT-IR techniques confirmed the production of the nanocomposite. AFM, SEM, and TEM were used to analyze the morphology of nanocomposite. The nanocomposites were found to be spherical using SEM. The synthesis of the nanocomposite was confirmed by the formation of chitosan in the presence of silver nanoparticles in TEM. Agar well diffusion was used to test the antibacterial properties of nanocomposites against Streptococcus, Rhizobium radiobacter, Klebsiella pneumoniae, and Escherichia coli. The findings demonstrated that silver nanoparticles with chitosan layer exhibited outstanding antibacterial and antioxidant properties, suggesting that they could be used as advanced biomedicine in the future.

\section{Data Availability}

The data used to support the findings of this study are included within the article.

\section{Conflicts of Interest}

The authors declare that there is no conflict of interest.

\section{Authors' Contributions}

SR designed, carried out research, and wrote the manuscript.

\section{Acknowledgments}

The study is funded by DST-SERB (file no. YSS/2014/000931), New Delhi, India.

\section{References}

[1] M. J. Sweet and I. Singleton, "Silver nanoparticles: a microbial perspective," Advances in Applied Microbiology, vol. 77, pp. 115-133, 2011.

[2] S. Ahmed, M. Ahmad, B. L. Swami, and S. Ikram, "A review on plants extract mediated synthesis of silver nanoparticles for antimicrobial applications: a green expertise," Journal of Advanced Research, vol. 7, no. 1, pp. 17-28, 2016.

[3] U. Kanagavalli, A. M. Sadiq, Sathishkumar, and S. Rajeshkumar, "Plant assisted synthesis of silver nanoparticles Using Boerhaavia diffusa Leaves extract and evolution of antibacterial activity," Research Journal of Pharmacy and Technology, vol. 9, no. 8, p. 1064, 2016.

[4] K. Paulkumar, G. Gnanajobitha, M. Vanaja et al., "Piper nigrum leaf and stem assisted green synthesis of silver nanoparticles and evaluation of its antibacterial activity against agricultural plant pathogens," Scientific World Journal, vol. 2014, article 829894, pp. 1-9, 2014.

[5] M. Gnanadesigan, M. Anand, S. Ravikumar et al., "Antibacterial potential of biosynthesised silver nanoparticles using $A v i$ cennia marina mangrove plant," Applied Nanoscience, vol. 2, no. 2, pp. 143-147, 2012.

[6] M. Vanaja, G. Gnanajobitha, K. Paulkumar, S. Rajeshkumar, C. Malarkodi, and G. Annadurai, "Phytosynthesis of silver 
nanoparticles by Cissus quadrangularis: influence of physicochemical factors," Journal of Nanostructure in Chemistry, vol. 3, no. 1, p. 17, 2013.

[7] P. Rajiv, S. Rajeshwari, and R. Venckatesh, "Bio-Fabrication of zinc oxide nanoparticles using leaf extract of Parthenium hysterophorus L. and its size-dependent antifungal activity against plant fungal pathogens," Spectrochimica Acta Part A: Molecular and Biomolecular Spectroscopy, vol. 112, pp. 384-387, 2013.

[8] S. Rajeshkumar, "Antioxidant activity of characterized silver nanoparticles synthesized using flower extracts of Chrysanthemum indicum," Research Journal of Biotechnology, vol. 12, no. 8, pp. 38-43, 2017.

[9] G. Gnanajobitha, S. Rajeshkumar, G. Annadurai, and C. Kannan, "Preparation and characterization of fruitmediated silver nanoparticles using pomegranate extract and assessment of its antimicrobial activities," Journal of Environmental Nanotechnology, vol. 2, no. 1, pp. 20-27, 2013.

[10] S. Singh, J. P. Saikia, and A. K. Buragohain, "A novel 'green' synthesis of colloidal silver nanoparticles (SNP) using Dillenia indica fruit extract," Colloids and Surfaces B: Biointerfaces, vol. 102, pp. 83-85, 2013.

[11] M. Amin, F. Anwar, M. R. S. A. Janjua, M. A. Iqbal, and U. Rashid, "Green synthesis of silver nanoparticles through reduction with Solanum xanthocarpum L. Berry extract : characterization, antimicrobial and urease inhibitory activities against Helicobacter pylori," International Journal of Molecular Sciences, vol. 13, no. 8, pp. 9923-9941, 2012.

[12] M. Ghaffari-Moghaddam and R. Hadi-Dabanlou, "Plant mediated green synthesis and antibacterial activity of silver nanoparticles using Crataegus douglasii fruit extract," Journal of Industrial and Engineering Chemistry, vol. 20, no. 2, pp. 739744, 2014.

[13] W. L. Du, Z. R. Xu, X. Y. Han, Y. L. Xu, and Z. G. Miao, "Preparation, characterization and adsorption properties of chitosan nanoparticles for eosin Y as a model anionic dye," Journal of Hazardous Materials, vol. 153, no. 1-2, pp. 152-156, 2008.

[14] J. Rhim, L. Wang, Y. Lee, and S. Hong, "Preparation and characterization of bio-nanocomposite films of agar and silver nanoparticles: Laser ablation method," Carbohydrate Polymers, vol. 103, pp. 456-465, 2014.

[15] J. S. Taurozzi, H. Arul, V. Z. Bosak et al., "Effect of filler incorporation route on the properties of polysulfone-silver nanocomposite membranes of different porosities," Journal of Membrane Science, vol. 325, no. 1, pp. 58-68, 2008.

[16] M. Sureshkumar, D. Y. Siswanto, and C. Lee, "Magnetic antimicrobial nanocomposite based on bacterial cellulose and silver nanoparticles," Journal of Materials Chemistry, vol. 20, no. 33, pp. 6948-6955, 2010.

[17] M. K. Shukla, R. P. Singh, C. R. K. Reddy, and B. Jha, "Synthesis and characterization of agar-based silver nanoparticles and nanocomposite film with antibacterial applications," Bioresource Technology, vol. 107, pp. 295-300, 2012.

[18] A. M. Youssef, M. S. Abdel-aziz, and S. M. El-sayed, "Chitosan nanocomposite films based on Ag-NP and Au-NP biosynthesis by Bacillus Subtilis as packaging materials," International Journal of Biological Macromolecules, vol. 69, pp. 185-191, 2014.

[19] P. L. L. Freire, A. J. R. Albuquerque, I. A. P. Farias et al., “Antimicrobial and cytotoxicity evaluation of colloidal chitosan silver nanoparticles - fluoride nanocomposites," International journal of biological macromolecules, vol. 93, no. Part A, pp. 896-903, 2016.
[20] J. W. Rhim, L. F. Wang, and S. I. Hong, "Preparation and characterization of agar/silver nanoparticles composite films with antimicrobial activity," Food Hydrocolloids, vol. 33, no. 2, pp. 327-335, 2013.

[21] P. Kaur, A. Choudhary, and R. Thakur, "Synthesis of chitosansilver nanocomposites and their antibacterial activity," International Journal of Scientific and Engineering Research, vol. 4, pp. 869-872, 2013.

[22] A. Nithya, H. L. JeevaKumari, K. Rokesh, K. Ruckmani, K. Jeganathan, and K. Jothivenkatachalam, "A versatile effect of chitosan-silver nanocomposite for surface plasmonic photocatalytic and antibacterial activity," Journal of Photochemistry \& Photobiology, B : Biology, vol. 153, pp. 412-422, 2015.

[23] G. Gnanajobitha, M. Vanaja, K. Paulkumar, and S. Rajeshkumar, "Green synthesis of silver nanoparticles using Millingtonia hortensis and evaluation of their antimicrobial efficacy," International Journal of Nanomaterials and Biostructures, vol. 3, no. 1, pp. 21-25, 2013.

[24] C. Krishnaraj, P. Muthukumaran, R. Ramachandran, M. D. Balakumaran, and P. T. Kalaichelvan, "Acalypha indica Linn: Biogenic synthesis of silver and gold nanoparticles and their cytotoxic effects against MDA-MB-231, human breast cancer cells," Biotechnology Reports, vol. 4, pp. 42-49, 2014.

[25] N. Nigam, S. Kumar, T. Ghosh, and P. K. Dutta, "Preparation of chitosan based silver nanocomposites by a facile method," in International Conference on Optics and Photonics, pp. 1-4, Chandigarh: CSIO, 2009.

[26] K. Shameli, M. B. Ahmad, Z. W. Yunis et al., "Green synthesis of silver/montmorillonite/chitosan bionanocomposites using the UV irradiation method and evaluation of antibacterial activity," International journal of nanomedicine, vol. 5, pp. 875-887, 2010.

[27] S. Rajeshkumar, C. Malarkodi, K. Paulkumar, M. Vanaja, G. Gnanajobitha, and G. Annadurai, "Algae mediated green fabrication of silver nanoparticles and examination of its antifungal activity against clinical pathogens," International Journal of Metalcasting, vol. 2014, article 692643, pp. 1-8, 2014.

[28] N. J. Reddy, D. Nagoor Vali, M. Rani, and S. S. Rani, "Evaluation of antioxidant, antibacterial and cytotoxic effects of green synthesized silver nanoparticles by Piper longum fruit," Materials Science and Engineering: C, vol. 34, pp. 115-122, 2014. 